\title{
Avaliação nutricional da alface cultivada em soluções nutritivas suprimidas de macronutrientes
}

\author{
Thiago Batista Firmato de Almeida* \\ Renato de Mello Prado \\ Marcus André Ribeiro Correia \\ Aline Peregrina Puga* \\ José Carlos Barbosa \\ PPG em Agronomia (Ciência do Solo) \\ Faculdade de Ciências Agrárias e Veterinárias \\ Universidade Estadual Paulista \\ Via de Acesso Prof. Paulo Donato Castellane, s/n, CEP 14.870-000, Jaboticabal - SP, Brasil \\ * Autores para correspondência \\ thibalmeida@gmail.com; linepuga@yahoo.com.br
}

Submetido em 30/11/2010

Aceito para publicação em 12/04/2011

\section{Resumo}

A alface é a mais popular das hortaliças folhosas, sendo conhecida mundialmente e o seu consumo ocorre principalmente na forma "in natura". Objetivou-se avaliar o efeito da omissão de macronutrientes no crescimento e no estado nutricional da alface cv. Verônica, bem como descrever sintomas visuais de deficiência nutricional. Os tratamentos foram: solução completa e omissão individual de N, P, K, Ca, Mg e S, sob delineamento inteiramente casualizado, com três repetições. As plantas foram cultivadas em solução nutritiva de Hoagland \& Arnon, em vasos (8L). Aos 56 dias após o transplantio, foram avaliados: a altura das plantas, o número de folhas, a área foliar, o índice SPAD, a matéria seca da parte aérea, das raízes e planta inteira, os teores dos macronutrientes da parte aérea e raízes e descrição das desordens nutricionais. As omissões dos nutrientes afetaram as variáveis de crescimento. Os teores de nutrientes observados nas plantas de alface do tratamento com solução nutritiva completa e da omissão, na parte aérea foram, respectivamente, $\mathrm{N}=23,2-9,5 ; \mathrm{P}=5,4-1,3 ; \mathrm{K}=58,9-3,2$; $\mathrm{Ca}=12,1-3,6 ; \mathrm{Mg}=5,5-0,7$ e $\mathrm{S}=3,2-1,5 \mathrm{~g} \cdot \mathrm{kg}^{-1}$. As omissões dos macronutrientes causaram prejuízos, pois afetaram a nutrição da hortaliça que refletiu em alterações morfológicas, traduzidas como sintomas característicos de deficiência de cada nutriente.

Palavras-chave: Deficiência nutricional, Lactuca sativa, Nutrição mineral

\section{Abstract}

Nutritional disorder of lettuce cv. Veronica in nutrient solution with suppressed macronutrients. Lettuce is the most popular of the leafy vegetables. It is known worldwide and its consumption occurs mainly in the natural form. The objective was to evaluate the effect of macronutrient omission on the growth and nutritional status of the lettuce cv. Veronica, and to describe the visual symptoms of nutritional deficiency. The treatments complete consisted of the solution and the individual omission of $\mathrm{N}, \mathrm{P}, \mathrm{K}, \mathrm{Ca}, \mathrm{Mg}$ and $\mathrm{S}$, under a 
completely randomized design with three replications. Plants were grown in Hoagland \& Arnon, in pots (8L). At 56 days after transplant we evaluated plant height, leaf number, leaf area, SPAD index, dry matter of shoots, roots and whole plant, levels of macronutrients in shoots and roots, and the nature of nutritional disorders. The omission of nutrients affected the growth variables. The nutrients found in lettuce plants from nutrient solution and the complete omission in the shoot were, respectively, $\mathrm{N}=23.2$ to $9.5, \mathrm{P}=5.4$ to $1.3, \mathrm{~K}=58,9$ to $3.2, \mathrm{Ca}=$ 12.1 to $3.6, \mathrm{Mg}=5.5$ to 0.7 and $\mathrm{S}=3.2$ to $1.5 \mathrm{~g} \cdot \mathrm{kg}^{-1}$. The omission of macronutrients caused quality losses, since it affected the nutrition of the vegetables and this resulted in morphological changes, reflected as symptoms of deficiency for each nutrient.

Key words: Lactuca sativa, Mineral nutrition, Nutritional deficiency

\section{Introdução}

A alface é a mais popular das hortaliças folhosas, sendo conhecida mundialmente e o seu consumo ocorre principalmente na forma “in natura”. Originária de clima temperado, a sua adaptação, em regiões de temperatura elevada, tem gerado obstáculos ao seu crescimento e desenvolvimento, impedindo que a cultura expresse todo o seu potencial genético. É uma das hortaliças mais difundidas atualmente, sendo cultivada por todo o país (LIMA, 2005). No entanto, o cultivo da alface entre os produtores destaca-se por se tratar de uma cultura de fácil manejo e por apresentar ciclo curto, garantindo rápido retorno do capital investido (KOEFENDER, 1998).

No Brasil, a cultura da alface tem uma área plantada de aproximadamente 35.000ha, sendo que o grupo que predomina é do tipo crespa. Neste grupo, enquadrase a cv. Verônica, liderando com $70 \%$ do mercado, enquanto o tipo americana detém $15 \%$ deste mercado (COSTA; SALA, 2005). Dentre as hortaliças de folhas, a alface é a mais plantada e consumida pela população brasileira. O estado de São Paulo é o principal produtor de hortaliças e tem o maior mercado consumidor do Brasil (CAMARGO FILHO; CAMARGO, 2008).

Em cultivos protegidos, a técnica hidropônica pode ser considerada a aplicação mais intensiva deste sistema agrícola de produção e, segundo Rodrigues (2002), é uma alternativa de cultivo de plantas com uso de soluções nutritivas balanceadas, na ausência ou na presença de substratos naturais ou artificiais.

$\mathrm{Na}$ literatura encontra-se uma série de sugestões de solução nutritiva para o cultivo da alface, porém, nesta área ressente-se da falta de pesquisa na área de nutrição de plantas, especialmente com relação às desordens nutricionais fato importante, pois pode afetar a produtividade e a qualidade das hortaliças.

Diante disso, objetivou-se avaliar o efeito da omissão de macronutrientes no crescimento e no estado nutricional da alface cv. Verônica, bem como descrever sintomas visuais de deficiência nutricional.

\section{Material e Métodos}

O experimento foi realizado na Faculdade de Ciências Agrárias e Veterinárias da UNESP, campus de Jaboticabal, estado de São Paulo, cujas coordenadas geográficas são: $21^{\circ} 15^{\prime} 22^{\prime}$ 'S $48^{\circ} 18^{\prime} 58^{\prime \prime O}$ e altitude de $575 \mathrm{~m}$, utilizando a cultura da alface, cv. Verônica, em vasos contendo $8 \mathrm{~L}$ de solução nutritiva.

Objetivou-se com o trabalho, avaliar o efeito da omissão de macronutrientes no crescimento e no estado nutricional da alface cv. Verônica, bem como descrever sintomas visuais de deficiência nutricional.

Os tratamentos foram constituídos por: 1- solução nutritiva completa $(\mathrm{N}, \mathrm{P}, \mathrm{K}, \mathrm{Ca}, \mathrm{Mg}, \mathrm{S}, \mathrm{B}, \mathrm{Cl}, \mathrm{Cu}, \mathrm{Fe}$, Mn, Mo e Zn); 2- omissão de nitrogênio (-N); 3- omissão de fósforo (-P); 4- omissão de potássio (-K); 5- omissão de cálcio (-Ca); 6- omissão de magnésio (-Mg); 7omissão de enxofre (-S), dispostos em um delineamento inteiramente casualizado, com três repetições.

A semeadura da alface foi realizada em bandeja de 200 células em substrato comercial Bioplant ${ }^{\circledR}$, sem adubação. Após a formação das primeiras folhas, dez dias após a emergência (DAE), duas plântulas foram transplantadas para vasos contendo $8 \mathrm{~L}$ de solução nutritiva de Hoagland e Arnon (1950), diluída a 50\% da concentração usual, mantidos durante a primeira semana 
de cultivo e solução a 100\% para a segunda semana de cultivo e após esse período até o final do experimento, utilizou-se a presente solução nutritiva sem a diluição. Alocaram-se os vasos na casa de vegetação, em bancadas a $1 \mathrm{~m}$ de altura do solo, distanciando de $0,4 \mathrm{~m}$ entre si. As soluções nutritivas foram substituídas a cada quinze dias e preparadas com água deionizada. $\mathrm{O}$ pH das soluções nutritivas foi monitorado diariamente, ajustando-se a $5,5 \pm 0,5$, usando-se solução $\mathrm{NaOH}$ ou $\mathrm{HCl} 0,1$ M.L-1 . Para a reposição da água evapotranspirada utilizou-se água deionizada, sendo a solução nutritiva oxigenada constantemente, através de compressor de ar.

Realizou-se durante a condução do experimento o rodízio dos vasos a cada semana, para proporcionar as mesmas condições de temperatura, umidade e luminosidade para os tratamentos.

As plantas foram colhidas após 56 dias após o transplantio (DAT). Nessa ocasião, determinou-se a altura das plantas, medida do colo da planta até o ápice da última folha desenvolvida e o número total de folhas por planta. Realizou-se a medida indireta do teor de clorofila a partir da leitura SPAD (Soil Plant Analysis Development) em dez folhas por unidade experimental com auxílio do aparelho da OPTI-Sciences ${ }^{\circledR}$ modelo CCM-200 e a área foliar foi medida com o aparelho LI-3100 Area Meter.

O material vegetal colhido foi lavado com água deionizada, separado em parte aérea e raízes e colocado para secar em estufa de ventilação forçada a $65^{\circ} \mathrm{C}$ até massa constante, determinando-se, então a matéria seca. Após, determinou-se os teores dos macronutrientes na matéria seca da parte aérea e das raízes, conforme método descrito por (BATAGLIA et al., 1983). Com os resultados da matéria seca da parte aérea (MSPA) e raízes (MSR) calculou-se a matéria seca da planta inteira (MSPI) e dos respectivos teores de nutrientes, realizou-se o cálculo do acúmulo desses nutrientes na parte aérea (APA), raiz (AR) e na planta inteira (API). Durante todo o período experimental, fizeram-se descrições da sintomatologia visual de deficiência nutricional nas plantas para cada tratamento.

Para os resultados obtidos, realizou-se a análise de variância e para comparação das médias, o teste de Tukey $(p<0,05)$, utilizando o software AGROESTAT
(BARBOSA; MALDONADO JR, 2010). Optou-se em indicar a diferença significativa apontada pelo teste de comparação de médias, em relação aos tratamentos com as omissões dos nutrientes (-N, -P, -K, -Ca, -Mg e -S) e o tratamento com solução nutritiva completa.

\section{Resultados e Discussão}

\section{Nitrogênio}

Com base nas avaliações de crescimento das plantas de alface com a omissão do nitrogênio observouse que o crescimento das plantas foi afetado de forma significativa, causando decréscimo na altura das plantas (AP), na área foliar (AF), no número de folhas (NF), na medida indireta da clorofila (SPAD) e na matéria seca das plantas (MSPL), quando relacionada ao tratamento com a solução nutritiva completa (Tabela 1).

A redução das variáveis de crescimento e da MSPL em função da omissão do nitrogênio é amplamente discutida na literatura. Segundo Filgueira (2003), o nitrogênio favorece o crescimento vegetativo, o acúmulo de massa, o aumento da área foliar e, consequentemente, a expressão do potencial produtivo da cultura. Esse fato ocorre devido ao efeito do nutriente na absorção iônica, fotossíntese, respiração, multiplicação e diferenciação celular (MALAVOLTA et al., 1997).

As plantas do tratamento com a omissão do nitrogênio apresentaram redução no índice SPAD. Os valores do índice SPAD foram de 5,27 e 2,43, respectivamente, para o tratamento com solução nutritiva completa e tratamento com omissão de $\mathrm{N}$ em solução nutritiva (Tabela 1), esse reflexo da planta pode ser explicado devido este nutriente estar relacionado com a formação da clorofila, pigmento que confere a cor verde aos tecidos dos vegetais.

No tratamento com solução nutritiva completa a planta apresentou teor de $\mathrm{N}$ na parte aérea e na raiz de $23,2 \mathrm{~g} \cdot \mathrm{kg}^{-1}$ e $36,2 \mathrm{~g} \cdot \mathrm{kg}^{-1}$, respectivamente, enquanto que no tratamento com omissão deste nutriente, o teor de $\mathrm{N}$ na parte aérea e raiz foi de $9,5 \mathrm{~g} \cdot \mathrm{kg}^{-1}$ e $9,8 \mathrm{~g} \cdot \mathrm{kg}^{-1}$, respectivamente (Tabela 2). Trani e Raij (1997) indicam como adequados para $\mathrm{N}$, teores de 30 a $50 \mathrm{~g} \cdot \mathrm{kg}^{-1}$. 
TABELA 1: Variáveis vegetativas das plantas de alface, em função da omissão de macronutrientes na solução nutritiva e da solução completa.

\begin{tabular}{|c|c|c|c|c|c|c|c|}
\hline \multirow{3}{*}{ Tratamentos } & \multirow{3}{*}{$\begin{array}{c}\text { Altura } \\
\text { de planta } \\
\text { (AP) } \\
\text { cm }\end{array}$} & \multirow{3}{*}{$\begin{array}{c}\text { Área foliar } \\
\text { (AF) } \\
\text { mm }\end{array}$} & \multirow{3}{*}{$\begin{array}{c}\text { Número } \\
\text { de folhas / } \\
\text { planta (NF) }\end{array}$} & \multirow{3}{*}{ SPAD } & \multicolumn{3}{|c|}{ Matéria seca } \\
\hline & & & & & $\begin{array}{l}\text { Parte aérea } \\
\text { (MSPA) }\end{array}$ & Raízes (MSR) & $\begin{array}{c}\text { Planta inteira } \\
\text { (MSPI) }\end{array}$ \\
\hline & & & & & \multicolumn{3}{|c|}{ g planta $^{-1}$} \\
\hline Solução completa & 59,16 & 1313,53 & 26,67 & 5,27 & 7,17 & 1,02 & 8,19 \\
\hline$-\mathrm{N}$ & $24,25^{*}$ & $230,80^{*}$ & $11,00^{*}$ & $2,43^{*}$ & $1,75^{*}$ & $0,53^{*}$ & $2,29^{*}$ \\
\hline$-\mathrm{P}$ & $15,17^{*}$ & $201,76^{*}$ & $13,00^{*}$ & $3,03^{*}$ & $1,10^{*}$ & $0,30^{*}$ & $1,37^{*}$ \\
\hline$-\mathrm{K}$ & $11,25^{*}$ & $102,33^{*}$ & $15,00^{*}$ & $3,83^{*}$ & $0,10^{*}$ & $0,10^{*}$ & $0,15^{*}$ \\
\hline$-\mathrm{Ca}$ & $8,77^{*}$ & $28,65^{*}$ & $4,67^{*}$ & $3,93^{*}$ & $0,15^{*}$ & $0,03^{*}$ & $0,18^{*}$ \\
\hline$-\mathrm{Mg}$ & $22,50^{*}$ & $466,10^{*}$ & $18,00^{*}$ & $4,37^{*}$ & $1,80^{*}$ & $0,17^{*}$ & $1,98^{*}$ \\
\hline$-\mathrm{S}$ & $41,77^{*}$ & $828,15^{*}$ & $20,33^{*}$ & $3,67^{*}$ & $4,80^{*}$ & $0,40^{*}$ & $5,16^{*}$ \\
\hline $\mathrm{F}$ & $232,85^{* *}$ & $146,16^{* *}$ & $104,44^{* *}$ & $31,40^{* *}$ & $412,83^{* *}$ & $209,61^{* *}$ & $504,76^{* *}$ \\
\hline DMS & 5,77 & 185,70 & 3,33 & 0,78 & 0,62 & 0,11 & 0,62 \\
\hline C.V. $\%$ & 7,9 & 14,7 & 7,7 & 7,4 & 9,3 & 11,2 & 8,2 \\
\hline
\end{tabular}

* Diferença significativa pelo teste Tukey $(\mathrm{p}<0,05)$, na coluna, em relação ao tratamento com a solução nutritiva com a omissão do nutriente e com a solução nutritiva completa. SPAD - Soil Plant Analysis Development.

TABELA 2: Teores de nutrientes na parte aérea e raízes das plantas de alface, em função da omissão de macronutrientes na solução nutritiva e da solução completa.

\begin{tabular}{|c|c|c|c|c|c|c|}
\hline Tratamentos & $\mathbf{N}$ & $\mathbf{P}$ & $\mathbf{K}$ & $\mathrm{Ca}$ & Mg & $\mathbf{S}$ \\
\hline & \multicolumn{6}{|c|}{ Parte aérea - g kg-1 $^{-1}$} \\
\hline Solução completa & 23,2 & 5,4 & 58,9 & 12,1 & 5,5 & 3,2 \\
\hline$-\mathrm{N}$ & $9,5^{*}$ & $28,4^{*}$ & $37,5^{*}$ & 0,0 & $26,0^{*}$ & $22,0^{*}$ \\
\hline$-P$ & $2,6^{*}$ & $1,3^{*}$ & $4,5^{*}$ & $3,4^{*}$ & 5,0 & $5,4^{*}$ \\
\hline$-\mathrm{K}$ & $34,8^{*}$ & $43,0^{*}$ & $3,2^{*}$ & $25,7^{*}$ & $45,8^{*}$ & $46,9^{*}$ \\
\hline$-\mathrm{Ca}$ & $4,9^{*}$ & 7,1 & $12,3^{*}$ & $3,6^{*}$ & $12,9^{*}$ & $12,2^{*}$ \\
\hline$-\mathrm{Mg}$ & $2,2^{*}$ & 2,6 & $6,7^{*}$ & $6,3^{*}$ & $0,7^{*}$ & 3,1 \\
\hline$-\mathrm{S}$ & $0,9^{*}$ & 3,2 & $2,9^{*}$ & $1,8^{*}$ & $3,6^{*}$ & 1,5 \\
\hline $\bar{F}$ & $256,29^{* *}$ & $685,68^{* *}$ & $1248,88^{* *}$ & $119,41^{* *}$ & $1970,76^{* *}$ & $2178,61^{* *}$ \\
\hline DMS & 3,9 & 3,0 & 3,0 & 3,9 & 1,8 & 1,7 \\
\hline \multirow[t]{2}{*}{ C.V. $(\%)$} & 12,5 & 8,2 & 5,9 & 18,6 & 4,5 & 4,5 \\
\hline & \multicolumn{6}{|c|}{ Raízes - g kg ${ }^{-1}$} \\
\hline Solução completa & 36,2 & 7,5 & 29,4 & 4,2 & 3,5 & 7,4 \\
\hline$-\mathrm{N}$ & $9,8^{*}$ & 0,0 & 0,0 & 0,0 & 0,0 & $36,1^{*}$ \\
\hline$-\mathrm{P}$ & $9,9^{*}$ & $1,9^{*}$ & $0,8^{*}$ & 0,0 & $8,8^{*}$ & 8,5 \\
\hline$-\mathrm{K}$ & $41,2^{*}$ & $36,4^{*}$ & $1,2^{*}$ & 0,0 & $28,3^{*}$ & $27,0^{*}$ \\
\hline$-\mathrm{Ca}$ & $0,2^{*}$ & $1,3^{*}$ & $0,6^{*}$ & 0,0 & 1,2 & $2,8^{*}$ \\
\hline$-\mathrm{Mg}$ & $1,5^{*}$ & $2,3^{*}$ & $0,4^{*}$ & 0,0 & 0,7 & $2,4^{*}$ \\
\hline$-\mathrm{S}$ & $2,2^{*}$ & 6,0 & $2,0^{*}$ & 0,0 & 4,8 & 6,4 \\
\hline $\bar{F}$ & $3186,27^{* *}$ & $835,70^{* *}$ & $272,54^{* *}$ & $1323,00^{* *}$ & $107,00^{* *}$ & $719,11^{* *}$ \\
\hline DMS & 1,5 & 2,1 & 3,2 & 0,2 & 4,6 & 2,4 \\
\hline C.V.(\%) & 3,6 & 9,7 & 23,1 & 12,6 & 24,7 & 6,6 \\
\hline
\end{tabular}

*Diferença significativa pelo teste Tukey $(\mathrm{p}<0,05)$, na coluna, em relação ao tratamento com a solução nutritiva com a omissão do nutriente e com a solução nutritiva completa. 
O APA, AR e o API foram afetados com a omissão de nitrogênio na solução nutritiva, sendo os teores encontrados na planta inteira, para o tratamento com solução nutritiva completa e a omissão, respectivamente, de 203,4mg.planta ${ }^{-1}$ e 21,8mg.planta ${ }^{-1}$ (Tabela 3).
Observou-se decréscimo da absorção de nitrogênio nas plantas cultivadas em solução nutritiva sem o nutriente, o que implicou na redução no desenvolvimento das plantas (Tabela 1) e no surgimento dos sintomas visuais característicos como, amarelecimento das folhas

TABELA 3: Nutrientes acumulados na parte aérea, raízes e na planta inteira de alface, em função da omissão de macronutrientes na solução nutritiva e da solução completa.

\begin{tabular}{|c|c|c|c|c|c|c|}
\hline Tratamentos & $\mathbf{N}$ & $\mathbf{P}$ & $\mathbf{K}$ & $\mathrm{Ca}$ & Mg & $\mathbf{S}$ \\
\hline & \multicolumn{6}{|c|}{ Parte aérea (APA) - mg.planta ${ }^{-1}$} \\
\hline Solução completa & 166,4 & 38,8 & 421,7 & 86,8 & 39,2 & 22,6 \\
\hline$-\mathrm{N}$ & $16,6^{*}$ & $49,7^{*}$ & $65,7^{*}$ & 0,0 & 45,7 & $38,5^{*}$ \\
\hline$-\mathrm{P}$ & $2,8^{*}$ & $1,4^{*}$ & $4,8^{*}$ & $3,7^{*}$ & $5,4^{*}$ & $5,9^{*}$ \\
\hline$-\mathrm{K}$ & $2,7^{*}$ & $3,4^{*}$ & $0,3^{*}$ & $2,0^{*}$ & $3,6^{*}$ & $3,7^{*}$ \\
\hline$-\mathrm{Ca}$ & $0,8^{*}$ & $1,1^{*}$ & $1,9^{*}$ & $0,5^{*}$ & $1,9^{*}$ & $1,8^{*}$ \\
\hline$-\mathrm{Mg}$ & $4,0^{*}$ & $4,7^{*}$ & $12,1^{*}$ & $11,4^{*}$ & $1,3^{*}$ & $5,6^{*}$ \\
\hline$-\mathrm{S}$ & $4,0^{*}$ & $15,6^{*}$ & $13,6^{*}$ & $8,4^{*}$ & $17,1^{*}$ & $7,2^{*}$ \\
\hline $\mathrm{F}$ & $548,66^{* *}$ & $131,31^{* *}$ & $1475,14^{* *}$ & $558,52^{* *}$ & $114,39^{* *}$ & $92,05^{* *}$ \\
\hline DMS & 12,6 & 8,4 & 19,5 & 6,4 & 8,4 & 6,8 \\
\hline \multirow[t]{2}{*}{ C.V. $(\%)$} & 16,0 & 18,4 & 9,4 & 14,3 & 18,6 & 20,0 \\
\hline & \multicolumn{6}{|c|}{ Raízes (AR) } \\
\hline Solução completa & 37,0 & 7,7 & 30,1 & 4,3 & 3,6 & 7,6 \\
\hline$-\mathrm{N}$ & $5,2^{*}$ & 0,0 & 0,0 & 0,0 & 0,0 & $19,2^{*}$ \\
\hline$-\mathrm{P}$ & $2,8^{*}$ & $0,6^{*}$ & $0,2^{*}$ & 0,0 & $2,6^{*}$ & $2,5^{*}$ \\
\hline$-\mathrm{K}$ & $3,3^{*}$ & $2,9^{*}$ & $0,1^{*}$ & 0,0 & $2,2^{*}$ & $2,2^{*}$ \\
\hline$-\mathrm{Ca}$ & 0,0 & 0,0 & 0,0 & 0,0 & 0,0 & $0,1^{*}$ \\
\hline$-\mathrm{Mg}$ & $0,3^{*}$ & $0,4^{*}$ & $0,1^{*}$ & 0,0 & $0,1^{*}$ & $0,4^{*}$ \\
\hline$-S$ & $0,9^{*}$ & $2,4^{*}$ & $0,8^{*}$ & 0,0 & $1,9^{*}$ & $2,5^{*}$ \\
\hline $\mathrm{F}$ & $1805,46^{* *}$ & $233,31^{* *}$ & $2517,23^{* *}$ & $346,69^{* *}$ & $56,27^{* *}$ & $523,73^{* *}$ \\
\hline DMS & 1,5 & 0,9 & 8,7 & 0,4 & 0,9 & 1,4 \\
\hline \multirow[t]{2}{*}{ C.V.(\%) } & 7,7 & 15,7 & 17,7 & 24,6 & 22,5 & 10,4 \\
\hline & \multicolumn{6}{|c|}{ Planta inteira (API)- } \\
\hline Solução completa & 203,4 & 46,5 & 451,7 & 91,0 & 42,7 & 30,2 \\
\hline$-\mathrm{N}$ & $21,8^{*}$ & 49,7 & $65,7^{*}$ & 0,0 & 45,7 & $57,8^{*}$ \\
\hline$-\mathrm{P}$ & $5,63^{*}$ & $1,9^{*}$ & $5,1^{*}$ & $3,7^{*}$ & $7,9^{*}$ & $8,3^{*}$ \\
\hline$-\mathrm{K}$ & $6,0^{*}$ & $6,3^{*}$ & $0,4^{*}$ & $2,0^{*}$ & $5,8^{*}$ & $5,8^{*}$ \\
\hline$-\mathrm{Ca}$ & $0,8^{*}$ & $1,1^{*}$ & $1,9^{*}$ & $0,5^{*}$ & $2,0^{*}$ & $1,9^{*}$ \\
\hline$-\mathrm{Mg}$ & $4,3^{*}$ & $5,1^{*}$ & $12,2^{*}$ & $11,4^{*}$ & $1,4^{*}$ & $6,0^{*}$ \\
\hline$-\mathrm{S}$ & $4,9^{*}$ & $18,0^{*}$ & $14,5^{*}$ & $8,4^{*}$ & $19,1^{*}$ & $9,7^{*}$ \\
\hline $\mathrm{F}$ & $713,96^{* *}$ & $140,21^{* *}$ & $1561,52^{* *}$ & $546,73^{* *}$ & $109,59^{* *}$ & $249,78^{* *}$ \\
\hline DMS & 13,4 & 8,6 & 20,3 & 6,8 & 8,7 & 6,2 \\
\hline C.V.\% & 13,7 & 17,8 & 9,2 & 14,6 & 17,6 & 12,9 \\
\hline
\end{tabular}

*Diferença significativa pelo teste Tukey $(\mathrm{p}<0,05)$, na coluna, em relação ao tratamento com a solução nutritiva com a omissão do nutriente e com a solução nutritiva completa. 
mais velhas seguidos de leve amarelecimento da planta em geral. Apresentou-se também, folhas de tamanho reduzido, menor desenvolvimento da planta e queda prematura das folhas. Conforme Malavolta et al. (1997), este sintoma está associado com a menor produção de clorofila, ocasionando modificação nos cloroplastos. Em face de sua deficiência há decréscimo no crescimento e causa má formação dos órgãos vegetativos, as folhas mais verdes amarelecem e caem com facilidade Faquin et al. (1994).

\section{Fósforo}

Observou-se que as plantas de alface que não receberam fósforo na solução nutritiva apresentaram diminuição na AP, na AF e no NF, refletindo na produção da MSPA, na MSR e na MSPI (Tabela 1). Evidenciando com isto, a função do fósforo na planta, pois o elemento nutriente está ligado à estrutura da mesma, no processo de transferência e armazenamento de energia, afetando vários processos metabólicos como a síntese de proteínas e ácido nucléico (MALAVOLTA, 2006).

Em relação ao tratamento com solução nutritiva completa e com a omissão de fósforo, os teores deste nutriente obtidos foram $5,4 \mathrm{~g} \cdot \mathrm{kg}^{-1}$ e $1,3 \mathrm{~g} \cdot \mathrm{kg}^{-1}$ na parte aérea, e, $7,5 \mathrm{~g} \cdot \mathrm{kg}^{-1}$ e $1,9 \mathrm{~g} \cdot \mathrm{kg}^{-1}$ nas raízes, respectivamente (Tabela 2). Notou-se que o tratamento com solução nutritiva completa apresentou teor de fósforo dentro da faixa considerada adequada pelos valores impostos por Trani e Raij (1997) (4 a 7g.kg-1), o tratamento com omissão do nutriente apresentou-se abaixo desta faixa. No entanto, são considerados altos por Malavolta et al. (1997) (3,5g. $\left.\mathrm{kg}^{-1}\right)$ e Nogueira Filho et al. (2003) $\left(4,1 \mathrm{~g} \cdot \mathrm{kg}^{-1}\right)$.

Houve incremento significativo para o fósforo nas plantas do tratamento com solução nutritiva completa em relação ao tratamento com omissão do nutriente, no APA, no AR, e no API que corresponderam a 38,8 e 1,4; 7,7 e 0,6; 46,5 e 1,9mg.planta ${ }^{-1}$, respectivamente (Tabela 3). Salienta-se que a absorção de fósforo pela cultura do alface varia em função do genótipo, o que na variedade utilizada neste trabalho a absorção é relativamente menor quando relacionada com a cultivar Locarno e Crespona Gigante, sendo semelhante apenas à cultivar Pira vermelha (SANCHEZ, 2007).
Nas plantas com omissão de fósforo ao diminuir a absorção do nutriente, conforme visto anteriormente proporcionou aparecimento de sintomas visuais, como diminuição acentuada no crescimento e desenvolvimento das plantas, as folhas mais velhas apresentaram uma coloração verde mais escura, ângulo estreito de inserção de folhas e atraso na maturidade.

\section{Potássio}

As variáveis vegetativas de crescimento foram afetadas significativamente pela omissão de potássio. Os tratamentos com solução nutritiva completa e com a omissão de potássio apresentaram decréscimo no desenvolvimento, com valores, 59,16 e $11,25 \mathrm{~cm}$; $1.313,53$ e $102,33 \mathrm{~mm} ; 26$ e $15 ; 5,27$ e 3,$83 ; 7,17$ e 0,10g.planta ${ }^{-1} ; 1,2$ e 0,10g.planta ${ }^{-1} ; 8,19$ e 0,15g.planta ${ }^{-1}$, respectivamente, para AP, AF, NF, índice SPAD, MSPA, MSR, e MSPI da alface (Tabela 1).

Houve diminuição no teor de potássio na parte aérea e raiz em comparação com o tratamento com solução nutritiva completa, resultando valores de $58,9 \mathrm{~g} \cdot \mathrm{kg}^{-1}$ e $3,2 \mathrm{~g} \cdot \mathrm{kg}^{-1}$ na parte aérea e $29,4 \mathrm{~g} \cdot \mathrm{kg}^{-1}$ e $1,2 \mathrm{~g}$. $\mathrm{kg}^{-1}$ nas raízes (Tabela 2). Essa redução de potássio na parte aérea, no tratamento com omissão do nutriente, representou uma queda de $55,7 \mathrm{~g} \cdot \mathrm{kg}^{-1}$ do nutriente no teor foliar. Para o tratamento com solução nutritiva completa, o teor está abaixo da faixa adequada indicada por Garcia (1982) (70 a 84g. $\mathrm{kg}^{-1}$ ) e Nogueira Filho et al. (2003) $\left(91,1 \mathrm{~g} \cdot \mathrm{kg}^{-1}\right)$. Sendo semelhantes aos obtidos pelas cultivares Crespona gigante e Locarno, e dentro da faixa recomendada por Haag e Minami (1988) (40g. $\mathrm{kg}^{-1}$ e 65g.kg-1). Já para Trani e Raij (1997) (50 a 80g.kg-1) os resultados obtidos estão dentro da faixa preconizada e está acima do indicado como adequado por Malavolta et al. (1997) (50g. $\left.\mathrm{kg}^{-1}\right)$.

Nas plantas com a omissão de potássio, pôde-se observar uma diminuição significativa de todos os macronutrientes no APA, no AR e no API, em relação às plantas que receberam o tratamento com solução nutritiva completa (Tabela 3).

A ausência do potássio na solução nutritiva diminuiu significativamente o crescimento e produção da matéria seca da parte aérea, raiz e planta inteira induzindo 
o surgimento de sintomas visuais característicos de desordem nutricional deste nutriente. As plantas de alface apresentaram sintomatologia de deficiência, perda de turgescência, flacidez, iniciando os sintomas com clorose seguido de escurecimento de pontos nas margens foliares mais velhas, afetando toda a folha e causando aspecto de queima necrótica, seguida da morte do tecido vegetal e posterior queda das folhas. Em face dessa sintomatologia, justifica-se pelo fato de o potássio agir na planta principalmente como ativador enzimático, regulador da abertura e fechamento dos estômatos, além de atuar como regulador do turgor celular.

\section{Cálcio}

Observou-se nas plantas que não receberam cálcio na solução nutritiva uma redução significativa na AP, na $\mathrm{AF}$, no $\mathrm{NF}$, assim como no índice SPAD quando comparadas com as plantas do tratamento com solução nutritiva completa, resultando em diminuição da produção da MSPA, MSR e MSPI (Tabela 1).

A fundamental importância do cálcio na planta é manter a integridade da parede celular (MALAVOLTA, 1980) e a sua desordem é caracterizada pelo surgimento de necrose, especialmente nas extremidades das folhas em desenvolvimento (COLLIER; TIBBITTS, 1982). Vale ressaltar que, o sistema radicular das plantas suprimidas de cálcio na solução nutritiva em relação ao tratamento com solução nutritiva completa, ficou apresentou um decréscimo de 97\%, com valores de matéria seca das raízes 1,02 e 0,03g.planta ${ }^{-1}$, respectivamente. Esse fato é explicado pela função do cálcio na planta, fazendo parte das pectinas por meio dos pectatos de cálcio, sendo requerido para a alongação e a divisão mitótica celular, refletindo diretamente no crescimento radicular (PRADO, 2008), justificando-se assim a extrema importância do cálcio no crescimento e aprofundamento das raízes.

Para os teores nutricionais, as plantas suprimidas de cálcio apresentaram menor teor do nutriente na parte aérea, já na raiz, não houve matéria seca para determinação do teor nutricional quando suprimido na solução nutritiva, sendo os teores de cálcio obtidos no tratamento completo e no tratamento com omissão do elemento, respectivamente, $12,1 \mathrm{~g} \cdot \mathrm{kg}^{-1}$ e $3,6 \mathrm{~g} \cdot \mathrm{kg}^{-1}$ na parte aérea e $4,2 \mathrm{~g} \cdot \mathrm{kg}^{-1}$ na raiz, com efeito significativo (Tabela 2).

Comparando com os dados de Trani e Raij (1997) (15 a 25g. $\left.\mathrm{kg}^{-1}\right)$ e Malavolta et al. (1997) (12,5g. $\left.\mathrm{kg}^{-1}\right)$ o teor do elemento na folha está baixo no tratamento com solução nutritiva completa. Essas diferenças no teor de cálcio do tratamento completo e o da literatura se dão possivelmente pela distinção do material vegetal analisado, pois no presente trabalho consideraram-se todas as folhas da parte aérea e não só apenas a coleta da folha diagnose como da literatura, bem como também a utilização de variedades distintas.

Para o APA, o AR e o API, respectivamente, 86,8; 4,3 e 91,0mg.planta ${ }^{-1}$, estes ocorreram em maior quantidade pelas plantas no tratamento com solução nutritiva completa, havendo decréscimo no tratamento com a omissão do nutriente para o APA $\left(0,5 \mathrm{mg}\right.$. planta $\left.^{-1}\right)$ e o API (0,5mg.planta $\left.{ }^{-1}\right)$ (Tabela 3$)$, para o AR não houve matéria seca para quantificar este acúmulo.

As plantas do tratamento com omissão de cálcio apresentaram sintomatologia de deficiência característica do nutriente suprimido, ocorrendo redução drástica no crescimento das plantas de alface, tanto da parte aérea como das raízes, folhas com formas irregulares, pontos com manchas necróticas entre as nervuras das folhas e morte das brotações a partir das pontas das extremidades de folhas e raízes, sintomas estes similares aos ocorridos pela literatura, ou seja, a deficiência de cálcio nas folhas pode apresentar deformações, especialmente das margens e uma torção de sua extremidade (HAAG, 1971). Salienta-se, que um dos principais problemas enfrentados pelos produtores de alface, tanto de sistema hidropônico como convencional, é o surgimento do "tipburn" ou "queima dos bordos", distúrbio fisiológico ocasionado pela deficiência localizada de cálcio (COLLIER; TIBBITTS, 1982), mesmo quando este nutriente encontra-se em níveis adequados no solo ou solução nutritiva (THIBODEAU; MINOTTI, 1969; ASHKAR; RIES, 1971).

\section{Magnésio}

Nas plantas do tratamento com omissão de magnésio na solução nutritiva, houve diminuição 
significativa na AP, na AF, no NF, no índice SPAD, bem como na MSPA, MSR e MSPI (Tabela 1).

Nas plantas submetidas à omissão de magnésio apresentaram menor teor do nutriente, na parte aérea $\left(0,7 \mathrm{~g} \cdot \mathrm{kg}^{-1}\right)$ comparado ao tratamento completo na parte aérea $\left(5,5 \mathrm{~g} \cdot \mathrm{kg}^{-1}\right)$ (Tabela 2$)$. Nas raízes os teores do nutriente do tratamento com solução nutritiva completa e no tratamento com omissão de magnésio foram de $3,5 \mathrm{~g}$. $\mathrm{kg}^{-1}$ e $0,7 \mathrm{~g} \cdot \mathrm{kg}^{-1}$, respectivamente, porém estes valores não apresentaram diferenças significativas (Tabela 2).

O teor de magnésio para as plantas do tratamento com a solução nutritiva completa teve valores pouco acima dos encontrados por Garcia (1982), Haag e Minami (1988) (3 a $5 \mathrm{~g} \cdot \mathrm{kg}^{-1}$ ) e Nogueira Filho et al. (2003) $\left(2,4 \mathrm{~g} \cdot \mathrm{kg}^{-1}\right)$. Trabalhando com a cv. Verônica (SANCHEZ, 2007) encontrou valores que se situam na faixa indicada como adequada segundo Trani e Raij (1997) (4 a 6g. $\left.\mathrm{kg}^{-1}\right)$.

Para o magnésio, o APA foi maior na parte aérea das plantas no tratamento com solução nutritiva completa (39,2mg.planta $\left.{ }^{-1}\right)$ em relação ao deficiente $(1,3 \mathrm{mg}$. planta $\left.^{-1}\right)$ (Tabela 3).

Contudo, apesar da diferença significativa dos teores de magnésio das plantas do tratamento com solução nutritiva completa em relação ao tratamento com solução nutritiva com omissão de magnésio na parte aérea, relatados anteriormente, os teores de $\mathrm{Mg}$ na raiz quando comparados com os teores de magnésio das raízes das plantas do tratamento com solução nutritiva completa verso solução com nutriente omitido, não apresentaram diferenças estatísticas (Tabela 2), entretanto, quando se avaliou o acúmulo de magnésio nas raízes houve redução do nutriente acumulado com efeito significativo apresentando redução de 97,2 \% para o AR e $96,7 \%$ para o API (Tabela 3 ).

Observou-se ainda com a omissão de magnésio, o desenvolvimento de sintomas de desordem nutricional nas plantas de alface, com clorose, iniciando-se entre as nervuras das folhas mais velhas. Isto, segundo Haag (1971) se deve ao fato do elemento ser facilmente mobilizado de locais da planta com maior concentração, possibilitando as folhas mais jovens retirá-lo das folhas mais velhas. Destaca-se que o magnésio é fundamental para a fotossíntese, sendo constituinte da molécula de clorofila, participando de inúmeras reações como ativador enzimático, da respiração, absorção iônica e transporte de energia, balanço eletrolítico e confere estabilidade aos ribossomos (MALAVOLTA et al., 1997).

\section{Enxofre}

Notou-se que a omissão deste macronutriente afetou a AP, a AF, o NF e o índice SPAD, quando comparado com o tratamento completo (Tabela 1).

As plantas submetidas à solução com omissão de enxofre, quanto ao teor do nutriente na parte aérea $(1,5 \mathrm{~g}$. $\mathrm{kg}^{-1}$ ), não diferiram significativamente, comparado ao tratamento com solução nutritiva completa. Também, nas raízes, o teor de enxofre ocorreu sem diferença estatística (Tabela 2). Com isso, percebe-se que a planta apresenta teores de enxofre acima dos indicados como adequados segundo Trani e Raij (1997), Malavolta et al. (1997) e Nogueira Filho et al. (2003), os quais estabelecem como valores indicados $\left(1,5 \mathrm{~g} \cdot \mathrm{kg}^{-1}\right.$ a $2,5 \mathrm{~g}$. $\left.\mathrm{kg}^{-1}\right) ;\left(2,5 \mathrm{~g} \cdot \mathrm{kg}^{-1}\right)$ e $\left(3,12 \mathrm{~g} \cdot \mathrm{kg}^{-1}\right)$, respectivamente. Para a cultura de alface, Sanchez (2007), trabalhando com a cv. Verônica encontrou teor de enxofre de $1,92 \mathrm{~g} \cdot \mathrm{kg}^{-1}$, acima do encontrado no presente trabalho.

Para o acúmulo deste elemento nas plantas de alface, houve redução significativa no APA, no API e no AR ocorrendo uma redução comparando-se os valores do tratamento completo com a omissão do elemento na solução nutritiva. O enxofre absorvido pelas plantas de alface apresentou maior valor no tratamento completo (APA: 22,6 e API: 30,2mg.planta-1 $)$ comparado ao suprimido de S (APA: 7,2 e API: 9,7mg.planta ${ }^{-1}$ ) (Tabela 3).

Em função da desordem nutricional de enxofre, notaram-se nas plantas de alface, folhas pequenas, com enrolamento nas margens das folhas, clorose, inicialmente nas folhas mais novas, cuja sintomatologia foi observada na fase final do experimento.

Malavolta et al. (1997) consideram o enxofre fundamental para as plantas, pois é constituinte dos aminoácidos cistina, metionina e cisteína, presente também em proteínas, sulfolipídeos, coenzimas e também age como ativador enzimático. 
Enfim, observou-se no tratamento com solução nutritiva completa a seguinte ordem decrescente quanto ao $\mathrm{APA}(\mathrm{K}>\mathrm{N}>\mathrm{Ca}>\mathrm{Mg}>\mathrm{P}>\mathrm{S})$, o $\mathrm{AR}(\mathrm{N}>\mathrm{K}>\mathrm{P}>\mathrm{S}>\mathrm{Ca}>\mathrm{Mg})$ e o API $(\mathrm{K}>\mathrm{N}>\mathrm{Ca}>\mathrm{P}>\mathrm{Mg}>\mathrm{S})$, destacando-se o potássio e o nitrogênio.

Sanchez (2007), trabalhando com cultivares de alface crespa em hidroponia, determinou a seguinte ordem decrescente quanto ao seu acúmulo de macronutrientes nas folhas: $\mathrm{K}>\mathrm{N}>\mathrm{Ca}>\mathrm{Mg}>\mathrm{P}>\mathrm{S}$, corroborando com a mesma sequência ocorrida neste experimento no tratamento com solução nutritiva completa. Os dados obtidos por Furlani (1995) e Cortez et al. (2000), ambos cultivando em sistema hidropônico obedeceram a seguinte ordem para a extração de macronutrientes: $\mathrm{K}>\mathrm{N}>\mathrm{Ca}>\mathrm{P}>\mathrm{Mg}$, sendo esta mesma sequência também obtida por Garcia (1982), só que em condições de solo. Nota-se, nestes dados da literatura, semelhanças com a do presente trabalho.

A partir dos resultados, foi possível concluir que as omissões dos nutrientes afetaram as variáveis de crescimento, AP, AF, NF e o índice SPAD refletindo na produção de MSPA. Já as omissões dos macronutrientes causaram prejuízos, pois afetaram a nutrição da hortaliça que refletiu em alterações morfológicas, traduzidas como sintomas característicos de deficiência de cada nutriente.

\section{Referências}

ASHKAR, S. A.; RIES, S. K. Lettuce tipburn as related to nutrient imbalance and nitrogen composition. Journal of American Society for Horticultural Science, Alexandria, v. 96, n. 4, p. 448452, 1971.

BARBOSA, J. C.; MALDONADO JR, W. AgroEstat - Sistema de análises estatísticas de ensaios agronômicos, Versão 1.0, Jaboticabal: Universidade Estadual Paulista, 2010. s/paginação.

BATAGliA, O. C.; FURLANI, A. M. C.; TEIXEIRA, J. P. F.; FURLANI, P. R.; GALLO, J. R. Métodos de análise química de plantas. Campinas: IAC, 1983. $48 \mathrm{p}$.

CAMARGO FILHO, W. P.; CAMARGO, F. P. Planejamento da produção sustentável de hortaliças folhosas: organização das informações decisórias ao cultivo. Informações Econômicas, São Paulo, v. 38, n. 3, p. 27-36, 2008.

CAStellane, P. D.; ARAúJo, J. A. C. Cultivo sem solo Hidroponia. 4 ed. Jaboticabal: FUNEP, 1995. 43 p.

COLLIER, G. F.; TIBBITTS, T. W. Tipburn of lettuce. Horticultural Reviews, Milton, v. 4, p. 49-65, 1982.

CORTEZ, G. P.; ARAúJO, J. A. C.; BELlingIERI, P. A. Cultivo de alface em hidroponia associada à criação de peixes. I. qualidade da água. Horticultura Brasileira, Brasília, v. 18, p. 192-193, 2000. COSTA, C. P.; SALA, F. C. A evolução da alfacicultura brasileira. Horticultura Brasileira, Brasília, v. 23, n. 1, artigo de capa, 2005. FAQUIN, V.; MARQUES, E. S.; SANTOS, H. S.; DUBOC, E. Crescimento e concentração de nitrato em alface sob influência da relação $\mathrm{NO}^{-}: \mathrm{NH}^{+}$e cloro na solução nutritiva e do horário de colheita. In: REUNIÃO BRASILEIRA DE FERTILIDADE DO SOLO E NUTRIÇÃO DE PLANTAS, 21, Petrolina, 1994. Anais... Petrolina, SBCS, 1994. p. 152-153.

FILGUEIRA, F. A. R. Novo manual de olericultura: agrotecnologia moderna na produção e comercialização de hortaliças. 2 ed. Viçosa: Universidade Federal de Viçosa, 2003. $412 \mathrm{p}$.

FURLANI, P. R. Cultivo de alface pela técnica de hidroponia NFT. Campinas: Instituo Agronômico de Campinas, 1995. 18 p.

GARCIA, L. L. C. Absorção de macro e micronutrientes e sintomas de carência de macronutrientes em alface (Lactuca sativa L.), cv. Brasil 48 e Clause's Aurélia. 1982.78 f. Dissertação (Mestrado em Agronomia) - Escola Superior de Agricultura Luiz de Queiroz, Universidade de São Paulo, Piracicaba. 1982.

HAAG, H. P. Manual de Adubação. São Paulo: Associação Nacional para Difusão de Adubos-ANDA, 1971. 256 p.

HAAG, H. P.; MINAMI, K. Nutrição mineral de hortaliças LXXV. Absorção de nutrientes pela cultura de almeirão. Anais da Escola Superior de Agricultura "Luiz de Queiroz", Piracicaba, v. 45, n. 2, p. 597-603, 1988.

HOAGLAND, D. R.; ARNON, D. I. The water culture method for growing plants without soils. Berkeley: California Agricultural Experimental Station, 1950. 347 p.

KOEFENDER, R. B. Hidroponia - como instalar e manejar o plantio de hortaliças dispensando o uso do solo. São Paulo: Nobel, 1998. 102 p.

LIMA, B. A. B. Avaliação de mudas de alface submetidas à adubação foliar com biofertilizantes cultivadas em diferentes substratos. 2005. 27 f. Monografia (Graduação em Agronomia) -ESAM, Mossoró. 2005.

MALAVOLTA, E. Elementos de nutrição mineral de plantas. São Paulo: Agronômica Ceres, 1980. 251 p.

MALAVOLTA, E. Manual de nutrição mineral de plantas. São Paulo: Editora Agrônomica Ceres, 2006. 638 p.

MALAVOlTA, E.; VITTI, G. C.; OliVeIRA, S. A. Avaliação do estado nutricional das plantas: princípios e aplicações. 2 ed. Piracicaba: POTAFÓS, 1997. 319 p.

NOGUEIRA FILHO, H.; SANTOS, O.; BORCIONI, E.; SINCHAK, S.; PUNTEL, R. Aquaponia: Interação entre alface hidropônica e criação superintensiva de Tilápias. Horticultura Brasileira, Brasília, v. 21, n. 2, s/paginação, 2003.

PRADO, R. M. Nutrição de plantas. São Paulo: Editora UNESP, 2008. $417 \mathrm{p}$.

RODRIGUES, L. R. F. Técnicas de cultivo hidropônico e de controle ambiental no manejo de pragas, doenças e nutrição vegetal em ambiente protegido. Jaboticabal: FUNEP. 765 p. 2002.

SANCHEZ, S. V. Avaliação de cultivares de alface crespa produzidas em hidroponia tipo NFT em dois ambientes protegidos em Ribeirão Preto-SP. 2007. 63 f. Dissertação (Mestrado em Agronomia). Faculdade de Ciências Agrárias e 
Veterinárias/Universidade Estadual Paulista - FCAV/UNESP, Jaboticabal. 2007

THIBODEAU, P. O.; MINOTTI, P. L. The influence of calcium on the development of lettuce tipburn. Proceedings of the American Society Horticultural Science, Alexandria, v. 94, p. 372-375, 1969.

TRANI, P. E.; RAIJ, B. Hortaliças. In: RAIJ, B.; CANTARELLA, H.; QUAGGIO, J. A.; FURLANI, A. M. C. (Eds). Recomendações de adubação e calagem para o Estado de São Paulo. 2 ed. rev. atual. Campinas: Instituto Agronômico/Fundação IAC, (Boletim Técnico, 100), cap. 18, 1997. p. 157-185. 